\title{
Diamond growth conditions and preservation: Inferences from trace elements in a large garnet inclusion in a Siberian diamond.
}

\author{
D.G. Pearson ${ }^{1}$, and H.J . Milledge ${ }^{2}$ \\ 1 Department of Geological Sciences, Durham University, South Rd, Durham, DH1 3LE, U.K. \\ 2 Department of Geological Sciences, University College London, Gower Street, London, UK
}

\section{Introduction}

The ability of syngenetic mineral inclusions in diamond to record detailed information on the chemical conditions prevailing during diamond growth, coupled with FTIR spectroscopic analyses for $\mathrm{N}$ content and aggregation of the host diamond provides an opportunity to gain valuable insights into diamond growth and evolution. In this study we have used SIMS to elementally characterise a large $(400 \mu \mathrm{m})$ garnet inclusion within a diamond from Udachnaya, Siberia, and FTIR spectroscopic analysis of the host diamond to try to provide such insights into the growth environment of this Ptype diamond.The garnet inclusion within a polished diamond plate was analysed for trace elements using a Cameca imf-4 ion-probe at Edinburgh University. The primary beam energy was $14.5 \mathrm{keV}$ and molecular interferences were surpressed using an energy offset of $75 \pm 20 \mathrm{eV}$. Elemental abundances were normalised to the SRM 610 glass standard.

\section{Results}

Sample 3649 contained a large (c. $400 \mu \mathrm{m})$ sub-calcic garnet inclusion with $11 \mathrm{wt} \% \mathrm{Cr}_{2} \mathrm{O}_{3}$ and c. 4.5 $\% \mathrm{CaO}$, plotting well into the "harzburgite field" of Sobolev (1974) and clearly belonging to the peridotite-suite. No obvious major elemental heterogeneity was observed in 12 electron microprobe analyses of the grain. 22 spot ion-probe analyses were obtained over the inclusion. At first sight the garnet inclusion appears as homogenous in trace elements as for major elements, especially in its REE content (Fig.la). Closer examination reveals some subtle, but distinct zonation. $\mathrm{Ba}$ and $\mathrm{La}$ vary by factors of c. 2, i.e., well outside the level of counting statistics, around the garnet rim, while the core is homogeneous at the level of counting statistics. Significant variability is observed for both $\mathrm{Y}$ and $\mathrm{Zr}$ (Fig. 1b) that are well outside counting statistics errors. The occurrence of trace element zonation within an inclusion that appears homogenous for major elements has been noted before (Shimizu et al. 1997) and suggests that caution is needed in assuming homogeneity within diamond inclusions. The core of 3649 garnet is subtly zoned, in $\mathrm{Y}$ and $\mathrm{Zr}$, in a linear trend that approximates the more significant zonation shown by the rim analyses, which show a strong positive linear covariation (Fig. 1b). $\mathrm{Zr}$ diffusion coefficients for garnet are not well known.. If we assume that $\mathrm{Y}$ diffusion coefficients are comparable to some of the HREE then the elemental zoning around the edge of this garnet cannot have persisted for 100's of Ma, implying a young age for the diamond. This raises the question of whether there is any evidence for open system behaviour in the host that may have allowed ingress of later fluids to cause such zonation. The host diamond to 3649 contains very little $\mathrm{N}(<50 \mathrm{ppm}$ ) but with some aggregation (c. $15 \% \mathrm{~N}$ as $\mathrm{B})$. Calculations suggest that for short mantle residence times $(0.1 \mathrm{Ga}$ or less) this diamond would have experienced temperatures as hot as $1250 \mathrm{C}$. 


\section{Conditions of garnet growth}

The shape of the REE pattern for 3649 (Fig. 1a) is the typical sinusoidal pattern observed for garnet inclusions in diamond (Shimizu and Richardson, 1987; Shimizu et al, 1997) and many garnets in low-T cratonic peridotites. This behaviour may reflect the lag of equilibrium versus crystal growth, where the garnet is encapsulated before it has achieved equilibrium with its growth medium (Shimizu et al, 1997). P-type garnet inclusions in diamonds commonly have low $\mathrm{Ti}$ and $\mathrm{Zr}$ contents and low $\mathrm{Ti} / \mathrm{Zr}$ (Fig. 1c), and this has been variously attributed, along with anomalously high $\mathrm{Sr}$ contents, to the influence of a carbonate-rich melt during growth of the garnet, and diamond (Griffin et al, 1993; Shimizu et al, 1997). Data for 3649 garnet (1100 ppm Ti, c. 95 ppm Zr), when considered with published data for other Siberian diamonds clearly indicates a different sub-population with relatively high $\mathrm{Ti}$ and very high $\mathrm{Zr}$ (Fig. 1c) that does not seem likely to be a carbonatite signature. Indeed, the high Sr content of P-type garnet inclusions, taken as being indicative of a carbonate-rich environment, seems specifically related to low $\mathrm{Zr}$ contents $(<20 \mathrm{ppm})$. The High $\mathrm{Zr}$ content and relatively low $\mathrm{Ti} / \mathrm{Zr}$ of some Siberian garnet inclusions is similar to the signature observed in garnets from the low-T garnet peridotite xenolith suite (Fig. 1c). Such a signature is distinct from the high $\mathrm{Ti} / \mathrm{Zr}$ characteristics of garnets from high-T lherzolite xenoliths that are more clearly related to basaltic melt interaction (Fig. 1c and d). These inferences are supported by the very high $\mathrm{Zr} / \mathrm{Y}$ of 3649 and similar Siberian inclusions. This shallow trending field in $\mathrm{Zr}-\mathrm{Y}$ space seen in xenolithderived garnets has been attributed to the influence of processes involving the growth of phlogopite. This same process may have caused the elemental signature seen in the high $\mathrm{Zr}$ garnet inclusions as they grew with diamond.

\section{Implications for diamond preservation}

Based on correlations between kimberlite diamond grades and garnet chemistry, Griffin and Ryan (1995) have proposed that metasomatic mantle processes involving enrichment of $\mathrm{Ti}, \mathrm{Zr}$ and $\mathrm{Y}$, similar to that observed for garnets from high-T peridotite xenoliths, has a detrimental effect on diamond preservation. No clear relationship was evident between garnet grade and the high $\mathrm{Zr}$, low $\mathrm{Y}$ signatures observed for garnets from low-T peridotites. Garnet inclusions from Siberian and Kaapvaal diamonds show evidence for both types of signature (Fig. 1d). Most garnet inclusions have very low Zr and Y, characteristic of highly depleted compositions (Griffin et al, 1992). A small fraction of the Siberian P-type garnet inclusion population show trends towards high $\mathrm{Zr}$ and $\mathrm{Y}$, with $\mathrm{Zr} / \mathrm{Y}$ between 2 and 5, characteristic of so-called "melt-metasomatised" garnets. A similar trend is shown by "lherzolitic" P-type garnet inclusions in diamonds from Ghana (Stachel \& Harris, 1997). This signature in some garnet inclusions in diamonds shows that some diamonds (albeit a very small fractions) may grow under such chemical conditions and raises the question of whether it is the "melt" or increased temperature that is deleterious to diamonds. Applying similar rationale to the high $\mathrm{Zr} / \mathrm{Y}$ signature it is evident that a reasonable proportion of the garnet inclusions analysed so far from Siberia and S. Africa have formed in this type of environment. Hence, what ever processes is causing this elemental fingerprint, it would be appear to be conducive to diamond crystallisation. If the high $\mathrm{Zr} / \mathrm{Y}$ signature indicates that phlogopite is crystallising from the same fluid/melt that the garnet and diamond formed from this raises the possibility of the phlogopite sequestering $\mathrm{N}$ during growth (mantle micas have high N contents; Sutton et al, 1989) and this may be the reason for the low $\mathrm{N}$ characteristics of the 3649 host diamond. This being further investigated by analysis of more garnets from low N/Type II diamonds. 
Fig. 1. 3649 garnet data plus literature data for P-type diamonds (see refs.).
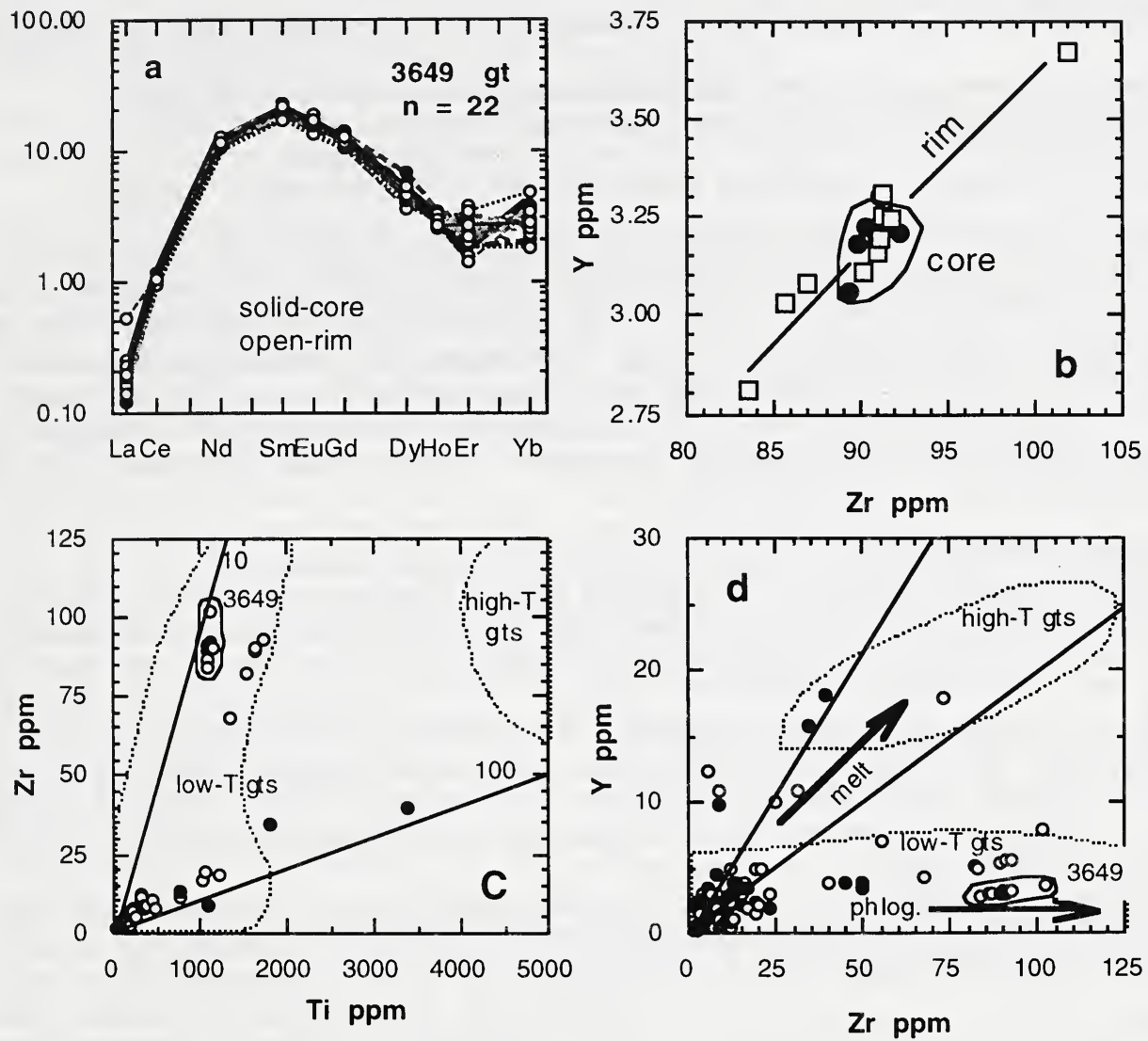

Griffin. W. L.. Gurney, J. J., and Ryan, C. G., 1992, Variations in trapping temperatures and trace elements in peridotite-suite inclusions from A frican diamonds: Evidence for two inclusions suites and implications for lithosphere stratigraphy: Contrib. Mineral. Petrol., v. 110, p. 1-15.

Griffin, W. L., Jaques, A. L., Sie, S. H., Ryan, C. G., Cousens, D. R., and Suter, G. F., 1988, Conditions of diamond growth; a proton microprobe study of inclusions in West Australian diamonds: Contributions to Mineralogy and Petrology, v. 99, p. 143-158.

Griffin, W. L., and Ryan, C. G., 1995, Trace elements in indicator minerals; area selection and target evaluation in diamond exploration: Journal of Geochemical Exploration, v. 53, p. 311-337.

Griffin, W. L., Sobolev, N. V., Ryan, C. G., Pokhilenko, N. P., Win, T. T., and Yefimova, E. S., 1993, Trace elements in garnets and chromites; diamond formation in the Siberian lithosphere: Lithos, v. 29, p. $235-256$.

Shimizu, N., and Richardson, S. H., 1987, Trace element abundance patterns of garnet inclusions in peridotite-suite diamonds: Geochimica et Cosmochimica Acta, v. 51, p. 755-758.

Shimizu, N., and Sobolev, N. V., 1995, Young peridotitic diamonds from the Mir kimberlite pipe: Nature (London), v. 375 , p. $394-397$.

Shimizu, N., Sobolev, N. V., and Yefimova, E. S., 1997, Chemical heterogeneities of inclusion garnets and juvenile character of peridotitic diamonds from Siberia: Russian Geology and Geophysics, v. 38, p. 356-372.

Sobolev, N. V., Lavrent'yev, Y. G., Pokhilenko, N. P., and Usova, L. V., 1973, Chrome-rich garnets from the kimberlites of Yakutia and their paragenesis.: Contrib. Mineral. Petrol., v. 40, p. 39-52.

Stachel, T., and Harris, J. W., 1997, Diamond precipitation and mantle metasomatism-evidence from the trace element chemistry of silicate inclusions in diamonds from Akwatia, Ghana.: Contrib. Mineral. Petrol., v. 129 , p. $143-154$.

Sutton, S. R., Smith, J. V., Jones, K. W., and Dawson, J. B., 1989, Nitrogen microanalyses of silicates using the $14 \mathrm{~N}(\mathrm{da}) 12 \mathrm{C}$ nuclear reaction and initial results on upper mantle and peralkaline magmatic micas: Nucl. Inst. Meth. Phys. Res., v. B36, p. 206-210. 